\title{
Epidemiological, Clinical and Paraclinical Aspects of Cirrhosis at Borgou Departmental University Hospital Center (Benin)
}

\author{
Comlan Albert Dovonou ${ }^{1,2}$, Cossi Adébayo Alassani ${ }^{*}$, Kadidjatou Sake1, \\ Cossi Angelo Attinsounon 1,2, Angèle Azon-Kouanou ${ }^{3}$, Agossou Romaric Tandjiekpon', \\ Djimon Marcel Zannou ${ }^{3}$, Fabien Houngbe ${ }^{3}$
}

\footnotetext{
${ }^{1}$ Medicine Department and Medical Specialities, Medical Faculty, Parakou University, Parakou, Benin ${ }^{2}$ Internal Medicine Department, Departmental Hospital Center of Borgou, Parakou, Benin ${ }^{3}$ Medicine Department and Medical Specialities of Cotonou Health and Science Faculty, Cotonou, Benin Email: *adebayoalassani@gmail.com
}

How to cite this paper: Dovonou, C.A., Alassani, C.A., Sake, K., Attinsounon, C.A., Azon-Kouanou, A., Tandjiekpon, A.R., Zannou, D.M. and Houngbe, F. (2018) Epidemiological, Clinical and Paraclinical Aspects of Cirrhosis at Borgou Departmental University Hospital Center (Benin). Open Journal of Internal Medicine, 8, 113-122.

https://doi.org/10.4236/ojim.2018.82012

Received: February 12, 2018

Accepted: March 31, 2018

Published: April 3, 2018

Copyright (C) 2018 by authors and Scientific Research Publishing Inc. This work is licensed under the Creative Commons Attribution International License (CC BY 4.0).

http://creativecommons.org/licenses/by/4.0/

\section{(c) (i) Open Access}

\begin{abstract}
Objective: To study the epidemiological, clinical and paraclinical aspects of cirrhosis at Borgou Departmental University hospital Center. Methods: This is a retrospective study for descriptive purpose conducted in the Internal Medicine Department. The study population consists of patients hospitalized in the Internal Medicine Department during the period from 1st January 2009 to 31st December 2016. Results: The frequency of cirrhosis was $1.35 \%$. The sex ratio was 3.76. The average age of patients was $45.22 \pm 15.23$ years old, with a range from 15 to 82 years. There is a post hepatitis Bcirrhosis predominance in $87.5 \%$ of cases, followed by alcoholic cirrhosis in $21.59 \%$ of cases. The complications of cirrhosis are dominated by ascites (78.4\%) and jaundice (52\%). Conclusion: Cirrhosis is a condition that is wide spread. The hepatitis B virusis the main cause of liver cirrhosis followed by alcoholism. Ascites is the most encountered complication. It's very important now to educate the populations for a behaviour change and to promote vaccination against viral hepatitis.
\end{abstract}

\section{Keywords}

Epidemiology, Hepatic Cirrhosis, Parakou, Benin

\section{Introduction}

Hepatic cirrhosis is a pathology characterized by the disorganization of liver architecture attributable to hepatocytes destruction since the hepatocellular regeneration remains in form of regeneration nodules with the presence of fibrosis. 
Nowadays, it's a public health problem [1]. The real world prevalence of hepatic cirrhosis is not well known but can exceed $1 \%$ if a liver biopsy and anatomopathological examination are realized for the benefit of the general population. In United State, Cirrhosis prevalence is $0.15 \%$ and represents respectively the tenth and the twelfth cause of death in men and in women, killing about 35,000 people every year [2]. In Europe, almost 170,000 of death related to cirrhosis are registered per year and represent $1.8 \%$ of all causes of death [3]. In Africa, the hospital prevalence of cirrhosis is at $7.02 \%$ in 2012 in Togo [4] and 2.35\% in 2008 in Mali [5]. In Cotonou (Benin), Sèhonou et al. have reported $22.6 \%$ as prevalence in 2006; Viral hepatitis Band chronic alcoholism are the most frequent reported causes [6]. No studies on hepatic cirrhosis have been performed in northern Benin. The present study was initiated to identify the different and the most common cause of hepatic cirrhosis. The results of this study will help prevent liver cirrhosis. The goal of this study is to describe the epidemiological, clinical and paraclinical aspects of cirrhosis in Borgou Departmental University hospital Center.

\section{Patients and Methods}

This is a retrospective study for a descriptive purpose conducted in the Internal Medicine Department. The study population consists of the patients hospitalized in the Internal Medicine Department from 1 St January 2009 to 31 St December 2016. We included only the patients with liver cirrhosis. Diagnostic criteria used for the diagnosis of liver cirrhosis were as follows:

- Signs in accordance with cirrhosis in the laboratory analyses: AST/ALT ratio $>1$, presence of thrombocytopenia, and prolonged prothrombin time.

- Imaging findings (ultrasonography and/or tomography): decrease in the liver size, parenchymal heterogeneity, superficial nodular changes, hypertrophy of the left lobe, splenomegaly and dilatation of portal vein.

- Clinical and endoscopic signs suggestive of cirrhosis; splenomegaly, esophageal varices, ascites, hepatic encephalopathy.

The study variables are:

- Epidemiological Data

o Frequency of liver cirrhosis. The diagnosis of cirrhosis is decided based on clinical and paraclinical arguments. Liver biopsy and anatomopathological examination were not done due to the lack of technical capacity means.

o Age of the patients

o The sex

- Clinical Data

o Functional signs

o History

o General signs

o Physical signs

- Paraclinical Data

o Liver function tests 
o Liver morphology explorations

The analysis has been done using the software Epi Data, version 3.1.

This study has used the data of a retrospective cohort. Neither the names nor others characteristics allowing the patients recognition were collected. The agreement of the National Ethics Committee for Health Research http://www.ethique-sante.org/) according to the recommendations was not requireddue to its retrospective character.

\section{Results}

\section{Epidemiological Data}

Out of 9260 patients who consulted or have been hospitalized in the Internal Medicine Department, 125 suffered from hepatic cirrhosis or a frequency at $1.35 \%$.

Among the cirrhotic patients, a male predominance has been noticed: 99 men for 26 women. The sex ratio was 3.76 .

Figure 1 shows cirrhotic patients distribution by age. The average age of the patients was $45.22 \pm 15.23$ years, with the extremes 15 and 82 years of age. About 8 out 10 patients were between the ages of 25 and 64 years old.

\section{Clinical characteristics}

Consultation period: All the patients were seen at a late phase with complications. The average period of consultation was $4.45 \pm 1.2$ months with the extremes 1 and 48 months; $60 \%$ of patients consulted three months after the first signs of decompensation.

Reason for consultation: dominated by abdominal pain (56.8\%), fever (43.2\%) and right hypochondrium lump (40\%).

Patient's history: Dominated by jaundice (36.8\%), alcoholism (29.6\%) and smoking (29.6\%).

$>$ The examination of the general condition found asthenia (83.2\%), weight loss (78.4\%), anorexia (70.4\%) and fever (37.6\%).

$>$ The physical signs were dominated by ascites (78.4\%), hepatomegaly (66.88\%) lower limb oedema (63.2\%). Table 1 shows the different signs found during the physical exam.

\section{Ascitic fluid examination}

Ascitic fluid was macroscopically yellow citrine (89.6\%), hemorrhagic (8.6\%) or cloudy (1.6\%).

> Cytobacteriological examination of the fluid showed a leukocyte count lower than $250 / \mathrm{mm}^{3}$ in $96.8 \%$ of the cases.

Table 2 points out the results of the ascitic fluid examination.

\section{Paraclinical characteristics}

Liver function tests

o The average level of prothrombin was 51.85\% $\pm 5.7 \%$.

o The average level of AST (Aspartate Aminotransferase) was $189.13 \pm 24.02$

$\mathrm{UI} / \mathrm{L}$ and the one of ALT (Alanine Aminotransferase) was $87.98 \pm 17.15$

$\mathrm{UI} / \mathrm{L}$. The ratio AST/ALT $\geq 1$ in $92.1 \%$ of cases. 


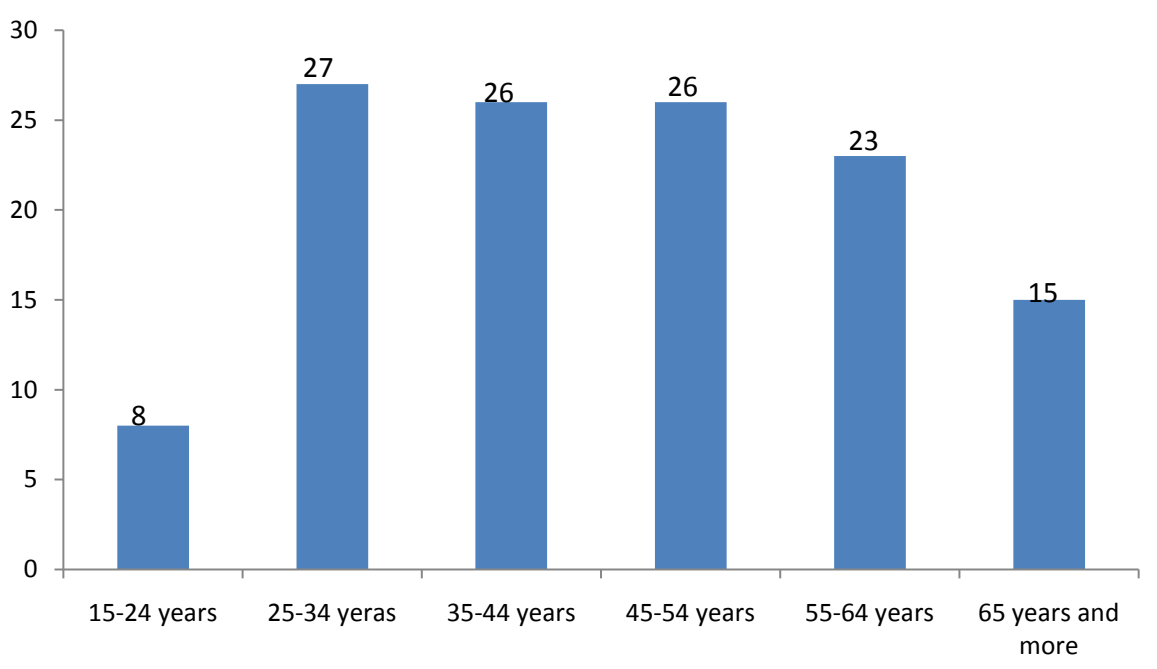

Figure 1. Distribution of the 125 cirrhotic patients by age groups.

Table 1. Physical signs found in 125 cirrhotic patients.

\begin{tabular}{ccc}
\hline & $\mathrm{n}$ & $\%$ \\
\hline Ascites & 98 & 78.40 \\
Lower limbs oedema & 79 & 63.20 \\
Clinical anemia & 74 & 59.20 \\
Jaundice & 65 & 52 \\
Hepatomegaly & 86 & 68.88 \\
Normal or atrophic liver & 39 & 31.12 \\
Splenomegaly & 70 & 56 \\
Collateral venous circulation & 50 & 40 \\
Pleurisy & 6 & 4.80 \\
Scarification & 11 & 3.20 \\
Flapping tremor & 4 & 8.80 \\
\hline
\end{tabular}

Table 2. Results of the ascites fluid examination in 125 cirrhotic patients.

\begin{tabular}{ccc}
\hline & $\mathrm{n}$ & $\%$ \\
\hline Citrine & Macroscopic aspects & \\
Hemorrhagic & 112 & 89.6 \\
Cloudy & 11 & 8.8 \\
& 2 & 1.6 \\
$<250 / \mathrm{mm}^{3}$ & White blood cells count & 96.8 \\
$\geq 250 / \mathrm{mm}^{3}$ & 121 & 3.2 \\
\hline
\end{tabular}


o The average value of totalbilirubinemia was $77.82 \pm 14.6 \mathrm{mg} / \mathrm{L}$ and varied from 1 to $498 \mathrm{mg} / \mathrm{L}$.

o The level of Gamma Glutamyl Transferase (GGT) varied from 39 to 3024 $\mathrm{UI} / \mathrm{L}$ with an average level at $413 \pm 33 \mathrm{UI} / \mathrm{L}$.

o The average level of alkaline phosphatase was $473.44 \pm 24.89 \mathrm{UI} / \mathrm{L}$ and varied from 138 to $1000 \mathrm{UI} / \mathrm{L}$.

The abdominal ultrasound focused on liver realized in 105 patients showed:

o The average size of the liver was $150.47 \pm 46.15 \mathrm{~mm}$ and varied between 50 and $250 \mathrm{~mm}$.

o The average size of the spleen was $156.10 \pm 41.11 \mathrm{~mm}$ and varied from 80 to $251 \mathrm{~mm} .56 .38 \%$ of patients had a splenomegaly.

o The average diameter of the portal vein was $15.87 \pm 2.27 \mathrm{~mm}$ with $21 \mathrm{~mm}$ as maximum.

Table 3 shows the observed signs by the abdominal ultrasonography.

Table 3. Results of abdominal ultrasonography in 105 cirrhotic patients.

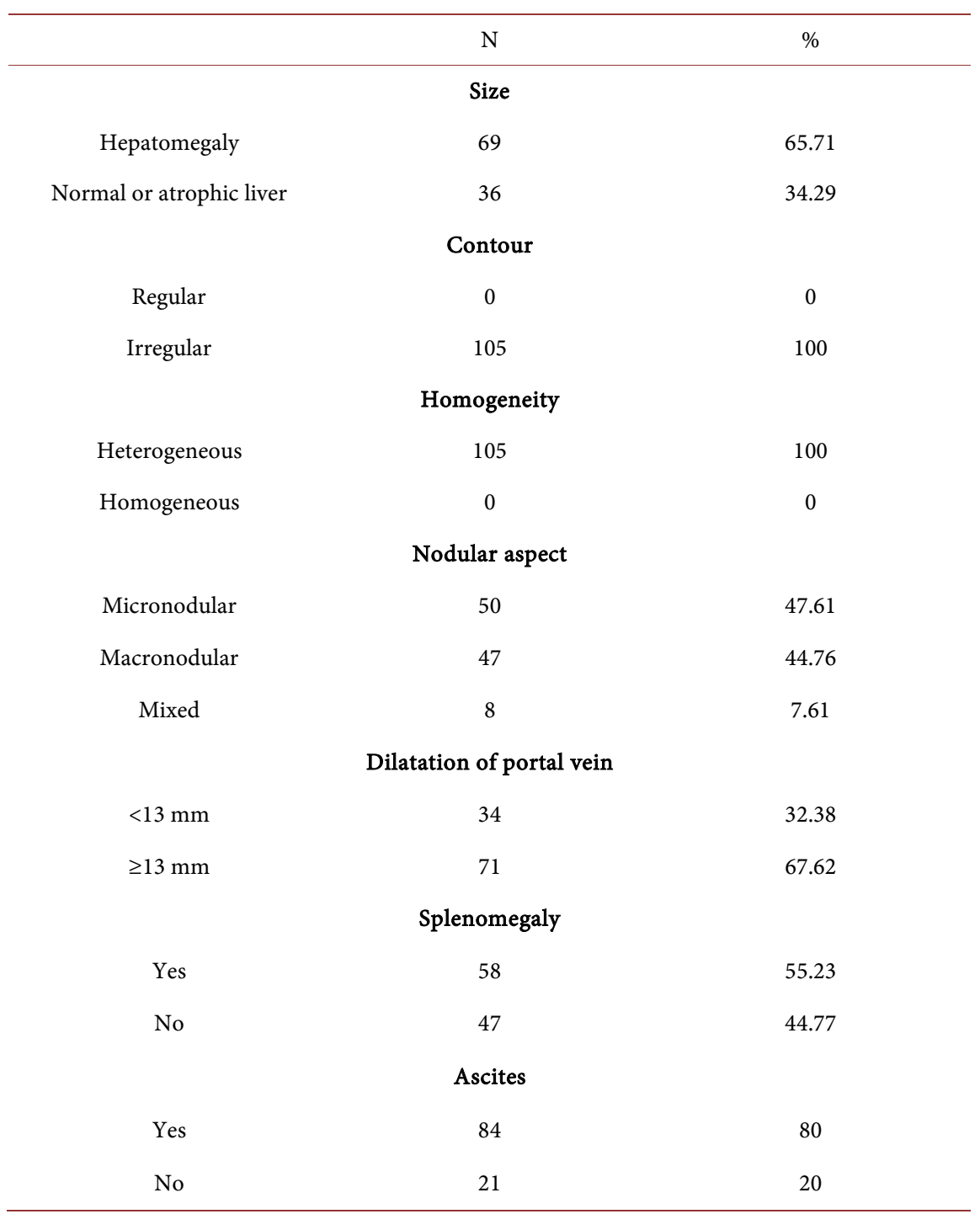


The etiology of cirrhosis has been identified in 87 cases with a predominance of post hepatitis B cirrhosis in 68 cases (87.5\%) followed by alcoholic liver cirrhosis in 11 cases (21.59\%). Figure 2 shows the etiologies of cirrhosis.

The complications of cirrhosis are dominated by ascites (78.4\%) and jaundice (52\%). Table 4 shows the complications of cirrhosis.

\section{Discussion}

The frequency of cirrhosis in Internal Medicine Department of Borgou Departmental University hospital Center was $1.35 \%$. The prevalence of cirrhosis is extremely variable from one country to another and from one continent to another. In West Africa Sèhonou et al. in 2006 [6] have reported $22.60 \%$ as frequency in Internal Medicine Department of National Teaching Hospital in Cotonou; Bouglouga et al. in 2012 [4] have reported a prevalence at $7.02 \%$ in Togo. The frequency of cirrhosis at $1.35 \%$ in Borgou Departmental University

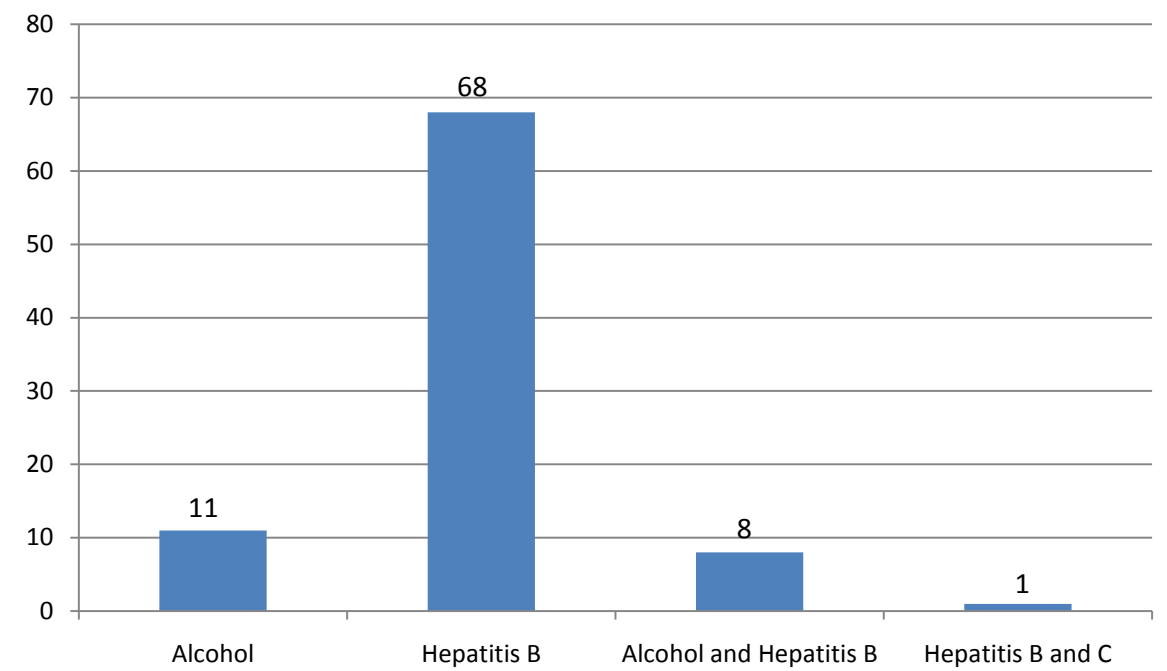

Figure 2. Patient distribution by etiologies of cirrhosis.

Table 4. Complications encountered in 125 cirrhotic patients.

\begin{tabular}{ccc}
\hline & $\mathrm{N}$ & $\%$ \\
\hline Ascites & 98 & 78.40 \\
Lower limbs oedema & 79 & 63.20 \\
Ascitesandoedema & 72 & 57.60 \\
Jaundice & 65 & 52 \\
Carcinoma & 64 & 51.20 \\
Biological anemia & 54 & 43.20 \\
Infection & 51 & 40.80 \\
Digestive hemorrhage & 25 & 20 \\
Kidney failure & 24 & 19.20 \\
Hepatic encephalopathy & 13 & 10.40 \\
\hline
\end{tabular}


hospital Center is lower than the one at $22.60 \%$ reported by Sèhonou et al. at National Teaching Hospitalin Cotonou. In reality, the prevalence reported by Sèhonou et al. was the one of hepatitis cirrhosis at the hepatogastroenterology department that usually receives patients suffering from digestive pathologies like chronic hepatopathies. The Internal Medicine Department of Borgou Departmental University hospital Centerreceives patients coming from all the medical specialities.

Among the 125 cirrhotic patients of our series, there were 99 men and 26 women with a sex ratio at 3.76. Many studies have reported a male predominance; the sex ratio varies between 1.38 and 4.6 [7] [8] [9]. Where as Houissa et al., reported a female predominance with a sex ratio at 0.83 [10].

The average age of our patients was $45.22 \pm 15.23$ years. That was similar to the one reported by many authors notably Sèhonou et al. (49 years of age) and Ouavene et al. (45 years) [6] [11]. In Turkey, en Greece and Romania, the average age of the cirrhotic patients was higher. Those authors have respectively reported 55.3 years, 56 years and 59 years [12] [13] [14]. That higher average age could be explained by the exposure to the hepatitis B virus (HBV) which was the main cause of cirrhosis in childhood in developing countries like Benin and also the absence of vaccination against that virus. Mother-to-child transmission is a real source of infection. This is augmented by unprotected sex mostly for teenagers.

All the patients were seen at a phase of decompensation, the average period for consultation was 4.45 months. In Togo, that has been observed by Bouglouga et al. who reported that $78.1 \%$ of patients consulted one year after the progression of the disease [4].

Among the patients history, jaundice and alcoholism account for respectively $36.80 \%$ and $29.60 \%$ of cases. According to the study of Ouavene et al., $63.5 \%$ had jaundice as history and $34 \%$ are chronic alcoholics [11].

Most of the patients had a poor general condition with asthenia (83\%) and loss of weight (78\%). The cirrhotic patients were undernourished. The prevalence of under nutrition during cirrhosis is approximately $50 \%$ at all the stages of the disease. That under nutrition is due to the reduction of food intake, a malabsorption and a hypercatabolism. The cirrhotic patient doesn't eat much since he is still anorexic, nauseous, with an altered sense of taste and a feeling of gastric fullness. According to the study of Xie et al., 56.6\% of the patients were asthenic and $34.1 \%$ were anorexic [15]. Hepatomegaly was found in $68.8 \%$ of cases, ascites $(78.40 \%)$ andsplenomegaly (56\%), collateral venous circulation (40\%) and abdominal pain (56.80\%). Hepatomegaly was the main morphological change reported by the authors [4] [6]. Aboutsplenomegaly and collateral venous, Bouglouga et al. [4] have respectively reported $13 \%$ and $5.2 \%$ and Ouavene et al. reported [11] 77.50\% and $95.50 \%$.

Hepatic ultrasonography realized showed hepatomegaly in $65.71 \%$ of cases. In the series of Ouavene et al. [11], hepatomegaly accounted for only $30 \%$ whereas the liver size was normal in $67.5 \%$ of cases. 
The analysis of the ascitic fluid revealed a leukocyte count inferior to $250 / \mathrm{mm}^{3}$ in $96.8 \%$ of cases, or an absence of infection encountered in most of noncomplicated hepatic cirrhosis [16]. Ouavene et al. have reported a yellow citrineascitic fluid (82\%) with a negative Rivalta's test results (76.7\%) [11]. In this study, the average level of prothrombin was $51.85 \%$ reflecting a hepatocellular insufficiency. In Togo, Bouglouga et al. have reported a decrease in the level of prothrombin at $70 \%$ in $85.5 \%$ of cases [4].

The average value of AST was $189.13 \mathrm{UI} / \mathrm{L}$ and the one of ALT was $87.98 \mathrm{UI} / \mathrm{L}$ with the ratio ASAT/ALAT $\geq 1$ in $92.1 \%$ of cases. Ouavene et al. reported a cytolysis in $71.50 \%$ of cases for the AST and $68 \%$ for the ALT [11]. Xie et al. have also reported a predominant hepatic cytolysis for the AST with a ratio AST/ALT at $2.00 \pm 1.20$ [15].

The average level of total bilirubinemia was $77.82 \mathrm{mg} / \mathrm{L}$, the one of Gamma GT was $413 \mathrm{UI} / \mathrm{L}$ and $473.44 \mathrm{UI} / \mathrm{L}$ for alkaline phosphatase witness of cholestasis. In their series, over half of the patients suffered from cholestasis according to Ouavene et al. [11].

In this study, hepatitis B virus is the main cause of hepatic cirrhosis (87.5\%) followed by chronic alcoholism (21.59\%). That predominance of post hepatitis B cirrhosis has been pointed out by Topdagi et al. who reported hepatitis B as the major cause of hepatic cirrhosis in the developing countries [12]. Post hepatitis cirrhosis are the most represented (54.5\%) followed by alcoholic cirrhosis (32.5\%) according to Ouavene et al. [11]. In his study conducted in Turkey, 52\% of hepatic cirrhosis were due to hepatitis B virus; Alcohol were found in $2 \%$ of cases. The low proportion of alcoholic cirrhosis could be explained by the low alcohol consumption in Muslim countries like Turkey. In Tunisia, viral causes (75\%) and mostly hepatitis C virus (62.5\%) have been reported as the main causes of hepatic cirrhosis. In developed countries, it's rather alcohol and hepatitis $C$ virus the main causes of hepatic cirrhosis [17]. In Germany, alcohol is responsible of hepatic cirrhosis for $52 \%$ followed by hepatitis C virus (28\%) and hepatitis B virus (14\%) [18]. Hepatic cirrhosis inescapably progresses to the complications [11]. In this study, many complications have been identified. Among these, ascites was observed in $78.40 \%$, hepatocellular carcinoma $51.20 \%$, jaundice $52 \%$, and infections $40.8 \%$.Similar results have been reported by many authors. Bouglouga et al. [4] have reported some complications like ascites, hepatocellular carcinoma and hepatic encephalopathy in respectively $60 \%, 26.3 \%$ and $7.5 \%$ of cases. Among the complications reported by Topdagi et al., there is an ascites predominance ( $83 \%$ ) followed by digestive hemorrhage (56\%), Peritonitis (42\%), hepatic encephalopathy (26\%) [12]. Xie et al. [15] and Bruno et al. [18] have reported an ascites predominance in respectively $60 \%$ and $76.65 \%$ of cases.

Esophageal varices have been observed in $60 \%$ of cases and ascites in $49 \%$ according to Kittner et al. [19].

This study has limits cause of limit number of patients and the type of study. Another study on a grand scale and cross sectional study would be necessary. 


\section{Conclusion}

Hepatic cirrhosis is a growing pathology. Hepatitis B virus is the main cause of hepatic cirrhosis followed by chronic alcoholism. Vaccination against hepatitis B virus and a decrease in alcoholic consumption are necessary in order to reduce the incidence of hepatic cirrhosis. That vaccination against hepatitis B virus is necessary from childhood especially in our developing countries.

\section{References}

[1] Ouavene, J.O., Koffi, B., Mobima, T., Bekondji, C., Massengue, A. and Guenebem, A.K. (2014) Cirrhoses du foie à l'hôpital de l'amitié de Bangui aspects épidémiologiques, cliniques, échographiques et problèmes de diagnostic. Journal African d Imagerie Médicale, 5, 1-12.

[2] Mokdad, A.A., Lopez, A.D., Shahraz, S., Lozano, R., Mokdad, A.H., Stanaway, J., et al. (2014) Liver Cirrhosis Mortality in 187 Countries between 1980 and 2010: A Systematic Analysis. BMC Medicine, 12, 145.

[3] Balkan, A., Alkan, S., Barutçu, S., Konduk, B.T., Yildirim, A.E. and Erdem, R. (2016) Etiological Distribution and Clinical Features of Cirrhotic Patients: Single Tertiary Referral Center Experience. Acta Medica Mediterranea, 32, 669-675.

[4] Verhelst, X., Geerts, A. and Vlierberghe, H.V. (2017) Cirrhosis: Reviewing the Literature and the Future Perspectives. European Medical Journal, 1, 111-117.

[5] Bouglouga, O., Bagny, A. and Djibril, M. (2012) Aspects épidémiologiques, diagnostiques et évolutifs de la cirrhose hépatique dans le service d'hépatogastroentérologie du chu campus de Lomé. J. Rech. Sci. Univ. Lomé(Togo), Série D, 14, 1-7.

[6] Diarra, M., Konaté, A. and Soukho (2010) Aspects évolutifs de la maladie cirrhotique dans un service d'hépato-gastro-entérologie au mali. Mali Médical, 14, 42-46.

[7] Sèhonou, J., Kodjoh, N., Saké, K. and Mouala, C. (2010) Cirrhose hépatique à Cotonou: Facteurs liés au décès. Médecinetropicale, 70, 375-378.

[8] Mohammed, S., Abdo, A. and Mudawi, H. (2016) Mortality and Rebleeding Following Variceal Haemorrhage in Liver Cirrhosis and Periportal Fibrosis. World Journal of Hepatology, 8, 1336-1342. https://doi.org/10.4254/wjh.v8.i31.1336

[9] Mathur, A., Chakrabarti, A., Mellinger, J., Volk, M., Day, R. and Singer, A. (2017) Hospital Resource Intensity and Cirrhosis Mortality in United States. World Journal of Gastroenterology, 23, 1857-1865. https://doi.org/10.3748/wjg.v23.i10.1857

[10] Zhang, X., Qi, X., de Stefano, V., Hou, F., Ning, Z. and Zhao, J. (2016) Epidemiology, Risk Factors, and in Hospital Mortality of Venous Thromboembolisme in Liver Cirrhosis: A Single Center Retrospective Observational Study. Medical Science Monitor, 22, 969-976. https://doi.org/10.12659/MSM.896153

[11] Houissa, F., Mouelhi, L., Amouri, N., Salem, M., Bouzaidi, S., Debbeche, R., et al. (2012) Factors Predicting Mortality in Infected Hospitalized Cirrhotics Patients: About 97 Cases. La Tunisie medicale, 90, 807-811.

[12] Topdagi, O., Okcu, N. and Bilen, N. (2014) The Frequency of Complications and the Etiology of Disease in Patients with Liver Cirrhosis in Erzurum. The Eurasian Journal of Medicine, 46, 110-114. https://doi.org/10.5152/eajm.2014.25

[13] Goulis, C.E., Arsos, J., Birtsou, G., Nakouti, C., Papadopoulou, S. and Akriviadis, E. (2013) Association between Ratio of Sodium to Potassium in Random Urine Sam- 
ples and Renal Dysfunction and Mortality in Patients with Decompensated Cirrhosis. Clinical Gastroenterology and Hepatology, 11, 862-867.

https://doi.org/10.1016/j.cgh.2013.02.005

[14] Onuigbo, W. (2016) The Prevention of Liver Cancer and the Epidemiology of Cirrhosis. Journal of Cancer Prevention and Current Research, 4, 132-133.

https://doi.org/10.15406/jcpcr.2016.04.00132

[15] Xie, Y., Feng, B., Gao, Y. and Wei, L. (2013) Characteristics of Alcoholic Liver Disease and Predictive Factors for Mortality of Patients with Alcoholic Cirrhosis. Hepatobiliary \& Pancreatic Diseases International, 12, 594-601. https://doi.org/10.1016/S1499-3872(13)60094-6

[16] Ascione, T., Flumeri, G., Boccia, G. and de Caro, F. (2017) Infections in Patients Affected by Liver Cirrhosis: An Update. Le Infezioni in Medicina, 1, 91-97.

[17] Da Silva, M., Miozzo, S., Dossin, I., Tovo, C., Branco, F. and de Mattos, A. (2016) Incidence of Hepatocellular Carcinoma in Outpatients with Cirrhosis in Brazil: A 10 Year Retrospective Cohort Study. World Journal of Gastroenterology, 22, 10219-10225. https://doi.org/10.3748/wjg.v22.i46.10219

[18] Bruno, S., Saibeni, S., Bagnardi, V., Vandelli, C., de Luca, M. and Felder, M. (2013) Mortality Risk According to Different Clinical Characteristics of First Episode of Liver Decompensation in Cirrhotic Patients: A Nationwide, Prospective, 3-Year Follow-Up Study in Italy. The American Journal of Gastroenterology, 108, 1112-1122. https://doi.org/10.1038/ajg.2013.110

[19] Kittner, S.V., Sprinzl, J.M., Weinmann, M.F., Wiltink, K.S. and Schattenberg, J.M. (2014) Etiology and Complications of Liver Cirrhosis: Data from a German Centre. Deutsche Medizinische Wochenschrift, 139, 1758-1762. 